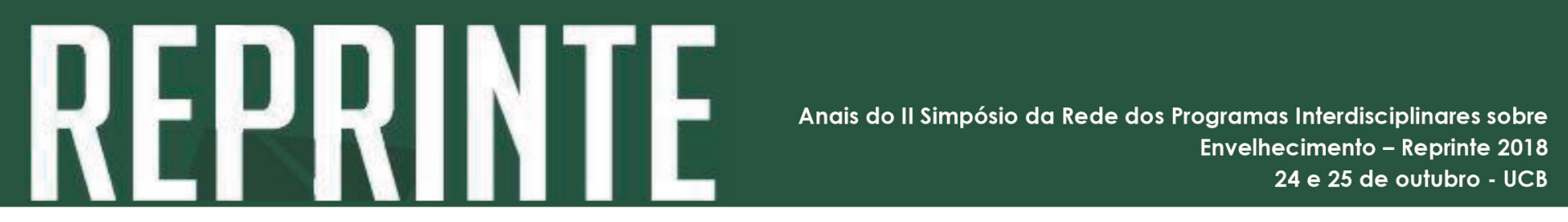

http://dx.doi.org/10.5335/rbceh.v16i1.10467

\title{
19) Nível de conhecimento e atitudes dos acadêmicos de enfermagem, acerca da sexualidade dos idosos
}

\begin{abstract}
Andreza Luiza Oliveira de Queiroz', Nayane Ferreira Vitorino'; Vitória Silva de Sousa'; Karla Helena Coelho Vilaça e Silva²; Andréa Paula Severiano ${ }^{3}$
\end{abstract}

Palavras-chave: Educação Sexual; Educação em Saúde; Idosos; Estudantes de Enfermagem.

\section{Introdução}

A resistência de muitos enfermeiros sobre a saúde sexual do idoso faz com que seja importante identificar se os acadêmicos de enfermagem têm embasamento teórico para essa temática e se possui uma atitude favorável para atendê-los quanto as suas dúvidas.

\section{Objetivos}

Identificar o nível de conhecimento e atitudes dos estudantes em enfermagem de instituições de ensino superior (IES), acerca da sexualidade dos idosos.

\section{Métodos}

Trata-se de uma pesquisa quantitativa, descritiva em corte transversal. Amostra de 301 alunos do último ano de graduação de IES. Aplicou-se o questionário da Escala de atitudes e conhecimento sobre sexualidade no envelhecimento (ASKAS). A análise estatística consistiu em trabalhar os dados coletados em frequência absoluta e relativa.

\footnotetext{
Alunas de enfermagem na Faculdade LS. Endereço para correspondência: St. D Sul QSA CL 5, 72015-040, Taguatinga, Brasil. Email (na ordem em que aparecem): andrezaluiiza@live.com; nayanefv@hotmail.com; silva.vitoria.sousa@ gmail.com

2 Professora no Programa de Pós-Graduação em Gerontologia da Universidade Católica de Brasília. Email: kavilaca@ yahoo.com.br

3 Mestranda do Programa de Pós-Graduação em Gerontologia da Universidade Católica de Brasília. Email: profandreaps@gmail.com
} 


\section{Resultados}

Verificou-se que houve falta de conhecimento assim como os alunos demonstraram posturas mais conservadoras e menos favoráveis na discussão do tema da sexualidade direcionada aos idosos (Tabelas 1, 2 e 3).

Tabela 1. Distribuição da amostra de formandos em enfermagem de acordo com a Instituição de Ensino Superior do Distrito Federal, Brasil, 2018.

\begin{tabular}{|c|c|c|c|}
\hline Instituiçåo de Ensino Superior & Local & Turno & $n(\%)$ \\
\hline IESA & Taguatinga Sul & Integral & $18(6,0)$ \\
\hline \multirow{2}{*}{ IES B } & \multirow{2}{*}{ Taguatinga Sul } & Matutino & $30(10,0)$ \\
\hline & & Noturno & $10(3,3)$ \\
\hline IESC & Gama & Matutino/ Noturno & $32(10,6)$ \\
\hline \multirow{2}{*}{ IESD } & \multirow{2}{*}{ Ceilàndia } & Matutino & $44(14,6)$ \\
\hline & & Noturno & $70(23,3)$ \\
\hline \multirow{2}{*}{ IESE } & \multirow{2}{*}{ Asa Sul } & Matutino & $30(10,0)$ \\
\hline & & Vespertino & $28(9,3)$ \\
\hline IESF & Asa Norte & Integral & $2(0,7)$ \\
\hline \multirow{4}{*}{ IESG } & \multirow{2}{*}{ Aguas Claras } & Matutino & $12(4,0)$ \\
\hline & & Noturno & $8(2,7)$ \\
\hline & Asa Norte & Matutino & $9(3,0)$ \\
\hline & Asa Sul & Noturno & $8(2,7)$ \\
\hline
\end{tabular}

\begin{tabular}{|c|c|c|c|c|}
\hline Afirmaçōes & $\begin{array}{l}\text { Discordo } \\
\text { fortemente } \\
n(\%)\end{array}$ & $\begin{array}{l}\text { Opinião dos f } \\
\text { Discordoemparte } \\
n(\%)\end{array}$ & $\begin{array}{c}\text { fmandos em ente } \\
\text { Náo concordo } \\
\text { nem discordo } \\
n(\%)\end{array}$ & $\begin{array}{c}\text { magem } \\
\text { Concordo } \\
\text { parte } \\
n(\%) \\
\end{array}$ \\
\hline $\begin{array}{l}\text { Evergonhoso para uma pessoa com mais de } 65 \text { anos mostrar } \\
\text { interesse por sexo. }(n=300)\end{array}$ & $253(84,3)$ & $22(7,3)$ & $9(3,0)$ & $14(4,7)$ \\
\hline $\begin{array}{l}\text { Casas de repouso nẩotêm obrigaçäo de garantir privacidade } \\
\text { para seus moradores que desejem ficar a sós com seus } \\
\text { parceiros. ( } n=299)\end{array}$ & $146(48,8)$ & $64(21,4)$ & $46(15,4)$ & $21(7,0)$ \\
\hline $\begin{array}{l}\text { O interesse sexual de uma pessoa com } 65 \text { anos ou mais } \\
\text { inevitavelmente desaparece. }(n=300)\end{array}$ & $118(39,3)$ & $86(28,7)$ & $49(16,3)$ & $39(13,0)$ \\
\hline $\begin{array}{l}\text { Eu apoiaria cursos sobre educação sexual para moradores de } \\
\text { casa de repouso. }(n=295)\end{array}$ & $38(12,9)$ & $20(6,8)$ & $24(8,1)$ & $39(13,2)$ \\
\hline $\begin{array}{l}\text { Eu apoiaria cursos sobre educação sexual para os funcionáíos } \\
\text { de casas de repouso. }(n=295)\end{array}$ & $39(13,2)$ & $17(5,8)$ & $26(8,8)$ & $50(16,9)$ \\
\hline $\begin{array}{l}\text { A masturbaçăo é uma atividade sexual aceitável para homens } \\
\text { com mais de } 65 \text { anos. ( } n=294 \text { ) }\end{array}$ & $36(12,2)$ & $21(7,1)$ & $69(23,5)$ & $62(21,1)$ \\
\hline $\begin{array}{l}\text { Instituiçōes como casas de repouso devem ter camas de casal } \\
\text { para os casais que desejem dormir junto. ( }(n=297)\end{array}$ & $41(13,8)$ & $34(11,4)$ & $47(15,8)$ & $55(18,5)$ \\
\hline $\begin{array}{l}\text { Os funcionários de cas as de repouso devem ser capacitados } \\
\text { para lidar com a sexualidade de pessoas com mais de } 65 \text { anos } \\
\text { com ou sem deficiência. ( } n=297 \text { ) }\end{array}$ & $39(13,1)$ & $16(5,4)$ & $10(3,4)$ & $32(10,8)$ \\
\hline
\end{tabular}




\begin{tabular}{|c|c|c|c|c|c|}
\hline \multirow[b]{2}{*}{ Afirmaçōes } & \multicolumn{5}{|c|}{ Opinião dos formandos em enfermagem } \\
\hline & $\begin{array}{l}\text { Discordo } \\
\text { fortemente } \\
n(\%)\end{array}$ & $\begin{array}{l}\text { Discordo em parte } \\
n(\%)\end{array}$ & $\begin{array}{l}\text { Ná concordo } \\
\text { nern discordo } \\
n(\%)\end{array}$ & $\begin{array}{l}\text { Concordoem } \\
\text { parte } \\
n(\%)\end{array}$ & $\begin{array}{l}\text { Concordo } \\
\text { totalmente } \\
n(\%)\end{array}$ \\
\hline $\begin{array}{l}\text { É vergonhoso para uma pessoa com mais de } 65 \text { anos mostrar } \\
\text { interesse por } \operatorname{sex} 0 .(n=300)\end{array}$ & $253(84,3)$ & $22(7,3)$ & $9(3,0)$ & $14(4,7)$ & $5(0,7)$ \\
\hline $\begin{array}{l}\text { Casas de repousonẩotêm obrigaçảo de garantir privacidade } \\
\text { para seus moradores que desejem ficar a sós com seus } \\
\text { parceiros. ( } n=299)\end{array}$ & $146(48,8)$ & $64(21,4)$ & $46(15,4)$ & $21(7,0)$ & $22(7,4)$ \\
\hline $\begin{array}{l}\text { O interesse sexual de uma pessoa com } 65 \text { anos ou mais } \\
\text { inevitavelmente desaparece. }(n=300)\end{array}$ & $118(39,3)$ & $86(28,7)$ & $49(16,3)$ & $39(13,0)$ & $8(2,7)$ \\
\hline $\begin{array}{l}\text { Eu apoiaria cursos sobre educação sexual para moradores de } \\
\text { casa de repouso. ( } n=295)\end{array}$ & $38(12,9)$ & $20(6,8)$ & $24(8,1)$ & $39(13,2)$ & $174(59,0)$ \\
\hline $\begin{array}{l}\text { Eu apoiaria cursos sobre educaçãos exual para os funcionátios } \\
\text { de casas de repouso. }(n=295)\end{array}$ & $39(13,2)$ & $17(5,8)$ & $26(8,8)$ & $50(16,9)$ & $163(55,3)$ \\
\hline $\begin{array}{l}\text { A masturbação é uma atividade sexual aceitável para homens } \\
\text { com mais de } 65 \text { anos. ( } n=294)\end{array}$ & $36(12,2)$ & $21(7,1)$ & $69(23,5)$ & $62(21,1)$ & $106(36,1)$ \\
\hline $\begin{array}{l}\text { Instituiçaes como casas de repouso devem ter camas de casal } \\
\text { para os casais que desejem dormir junto. ( } n=297)\end{array}$ & $41(13,8)$ & $34(11,4)$ & $47(15,8)$ & $55(18,5)$ & $120(40,4)$ \\
\hline $\begin{array}{l}\text { Os funcionários de casas de repouso devem ser capacitados } \\
\text { para lidar com a sexualidade de pessoas com mais de } 65 \text { anos } \\
\text { com ou sem deficiência. ( } n=297 \text { ) }\end{array}$ & $39(13,1)$ & $16(5,4)$ & $10(3,4)$ & $32(10,8)$ & $200(67,3)$ \\
\hline
\end{tabular}

\section{Conclusão}

Sugere uma revisão do aporte teórico ofertado aos acadêmicos de enfermagem bem como práticas junto aos idosos para que a promoção/prevenção sobre sua sexualidade seja efetivamente alcançada.

\section{Level of knowledge and attitudes of nursing students about the sexuality of the elderly}

Keywords: Sexual Education; Health education; Seniors; Nursing students. 